\title{
Update on the management of adolescent varicocele
} Kenneth I Glassberg* and Ruslan Korets

\author{
Address: Division of Pediatric Urology, Morgan Stanley Children's Hospital of New York - Presbyterian, Department of Urology, \\ Columbia University College of Physicians and Surgeons, 3959 Broadway, New York, NY 10032, USA \\ *Corresponding author: Kenneth I Glassberg (kg2109@columbia.edu) \\ FI000 Medicine Reports 2010, 2:25 (doi:10.3410/M2-25)
}

The electronic version of this article is the complete one and can be found at: http://fl000.com/reports/medicine/content/2/25

\begin{abstract}
The management of adolescent varicocele has evolved over the last 30 years. This article briefly reviews some of the current issues regarding the adolescent varicocele, including (a) the progressive nature of the adolescent varicocele, (b) the degree of asymmetry that necessitates surgery, (c) the wide variability in percentage of repairs performed bilaterally in published adolescent series, and (d) the choice of surgical procedure to be performed.
\end{abstract}

\section{Introduction and context}

The incidence of varicoceles in both men and adolescent boys is approximately $15 \%$ [1-3]. In men evaluated for an infertility problem, $37-41 \%$ are diagnosed with a left varicocele but only $40 \%$ will achieve paternity when the varicocele is surgically corrected $[4,5]$. It would be illogical to recommend varicocele repair on any adolescent male just because he has a varicocele, given that well above the majority will have no problem with infertility. Yet when abnormal semen parameters do occur, they can often be detected, even in teenage boys [6,7]. Therefore, it is worthwhile to determine who might benefit from surgery, even in adolescence, in order to prevent the development of abnormal semen parameters in the future or perhaps in order to reverse damage already suffered by the testis in those with already abnormal semen parameters.

\section{Recent advances}

\section{Progressive disease}

When Kass and Belman [8] observed that $80 \%$ of boys with a left varicocele and ipsilateral hypotrophy exhibit catch-up growth following surgery, it opened the door to prophylactic varicocelectomy in cases of ipsilateral asymmetry with the hope of preventing infertility when older. In 1997, Sigman and Jarow [9] reported that, in adults, the combination of a large varicocele and ipsilateral hypotrophy was associated with a higher incidence of abnormal semen parameters, which led the authors to conclude that the practice of varicocelectomy for ipsilateral testicular hypotrophy in adolescents was indeed valid. In addition, others have shown that once ipsilateral hypotrophy is present in a man's 20s, it is likely to be worse in his 30 s and semen parameters are more likely to worsen with age, particularly when hypotrophy is present $[10,11]$. Similarly, Haans et al. [12] found decreased sperm counts in 17- to 20-year-old boys with a left varicocele, but only in those with ipsilateral hypotrophy. Even in adolescents, the effect of the varicocele can be progressive, as illustrated by a Japanese study that reported on 24 boys who had varicocelectomy and 16 boys who were followed conservatively [13]. Sixty-seven percent of the boys who had surgery had initial left hypotrophy, and following surgery only $24 \%$ of the boys had hypotrophy. However, of the boys followed conservatively, $50 \%$ had asymmetry initially, and on follow-up, $75 \%$ had ipsilateral hypotrophy.

\section{Asymmetry}

The most used formula for left asymmetry is as follows: ([right testis volume - left testis volume]/right testis volume) $\times 100$; volumes are measured in cubic centimeters. Various size discrepancies between the testes have been used to indicate clinically relevant asymmetry, including $10 \%$ or greater, $15 \%$ or greater, and $20 \%$ or greater and a volume difference of 2-3 cc between testes 
[14-16]. Aside from the debate relating to what cutoff to use, there is a debate regarding how long patients should be followed with asymmetry before deciding on surgery. One recent publication, by Diamond et al. [17], reported a significantly higher incidence of patients with decreased sperm concentration and decreased total motile sperm in patients with a sonographically derived volume differential of as little as $10 \%$. Of the 57 boys in their study, those with volume differentials of $10-20 \%$ had an $11 \%$ chance of having a subnormal total motile sperm count. If the testicular differential exceeded $20 \%$, the total motile sperm count was abnormal in 59\%. The authors recommend varicocelectomy when a greater than $20 \%$ asymmetry is identified and persists for more than 1 year, whereas others have suggested following patients with asymmetry even longer since catch-up growth was found in $71 \%$ of boys at a mean of 3 years without any intervening surgery [18].

Our findings, however, have found a much lower incidence of catch-up growth in boys without surgical intervention. Poon et al. [19] performed a retrospective review of the institutional varicocele database and identified 181 boys who were followed expectantly and had at least two ultrasound measurements. Thirty-five percent of patients who initially had less than $20 \%$ asymmetry had at least $20 \%$ asymmetry on follow-up, whereas $53 \%$ of patients with at least $20 \%$ asymmetry had a continued asymmetry of at least $20 \%(P=0.007)$. Although numerous studies have demonstrated ipsilateral testicular growth and improved semen analysis after adolescent varicocelectomy, only one study has reported on the effect of surgery during adolescence on subsequent paternity [20]. Questionnaires inquiring as to the marital and paternity status were sent to a select group of Hasidic Jewish patients who were at least 21 years old and who had undergone a unilateral or bilateral varicocele repair during adolescence. Of the 43 responders, 25 were not married or had never attempted to father a child whereas the remaining 18 had attempted to father a child and were all successful.

We also have been evaluating peak retrograde flow (PRF), a measurement identified by Doppler ultrasound, and have used it to help provide another objective measurement that might play a role in decision making of varicocele patients. After all, Doppler flow studies can easily be obtained since many pediatric urologists already have been using ultrasound to access testicular volume $[21,22]$. Some studies have suggested that ultrasound is more reliable than either Prader or ring orchidometers for determining volume. We have found that among a subset of 22 patients who had at least $20 \%$ asymmetry and PRF of at least $38 \mathrm{~cm} / \mathrm{s}$, only one patient
(4.5\%) achieved less than 20\% asymmetry on follow-up [19]. On the other hand, if the initial volume differential was less than $20 \%$ and PRF was less than $30 \mathrm{~cm} / \mathrm{s}$, a differential of at least $20 \%$ was unlikely to develop [23]. These findings, in conjunction with our experience of more than 1200 Doppler ultrasounds of adolescent varicoceles, suggest that PRF may provide a quantitative role in predicting persistence of ultimate testicular volume differentials, thereby guiding decision making for earlier surgery in appropriate cases.

\section{Bilaterality}

While varicoceles are traditionally viewed as a left-sided disease, the presence of a right-sided varicocele, either subclinical (i.e., present on ultrasound but not palpable) or clinical (i.e., palpable), in the setting of left-sided varicocele is well described, especially in the adult literature. In the contemporary adult varicocelectomy series, the median incidence of bilateral repair is $38 \%$ (range 3-73\%). In most of these series, subclinical varicocele (i.e., not palpable, but displaying retrograde flow on duplex Doppler ultrasound [DDUS]) is not included. However, documentation of right-sided varicocelectomies is far less commonly reported in pediatric series, with a median incidence of just $4 \%$ (range $0-48 \%$ ). As we routinely obtain Doppler ultrasounds on just about all of our patients with a grade 2 or 3 left varicocele, we feel we have become more sensitized to the existence of a contralateral right varicocele (both clinical and subclinical). Using Doppler ultrasound, we examined 518 boys with a grade 2 or 3 left varicocele and identified right retrograde flow in $40.2 \%$ of our patients with a left varicocele, and in our hands, the right varicocele was palpable in greater than $50 \%$ of those with flow as well, although much smaller than on the left. In other words, our findings regarding right varicoceles in adolescents are very similar to the findings in adults and contrary to what some pediatric urologists perceive. After all, why should the incidence of right varicocele in patients with a left varicocele be so different between adolescents and adults? While we recognize that there is a greater likelihood of palpating a right varicocele when one knows beforehand that right retrograde flow exists, one must be aware of indolent right varicoceles and the possibility of being misled by lower levels of testicular asymmetry in these patients, as we have been finding in our series. While we would not operate on any of the subclinal right varicoceles, we do feel that there is a role for operating on some of the larger right varicoceles when operating on the left. In addition, in some left varicoceles that we consider borderline for surgery, the presence of a palpable right varicocele might tip the balance toward surgery. At present, there are no guidelines for determining which right varicoceles should 
undergo simultaneous repair but hopefully, in the future, guidelines as to who should undergo repair on the right side while operating on the left will be developed on the basis of palpability and DDUS findings in addition to degree of asymmetry.

\section{Choice of repair}

Before procedures like laparoscopic varicocelectomy and microscopic subinguinal repairs became popular, it was believed that the incidence of varicocelectomy failures was higher in children than adults, particularly with the Ivanissevich repair. While it might be possible that pediatric urologists were not as good as their adult urologic colleagues in repairing a varicocele through what at the time was traditionally an inguinal approach, it could have been that pediatric urologists were more critical than adult urologists in evaluating their results. Perhaps adult urologists were more focused on improvement in semen parameters than on complete disappearance of the varicocele. The Ivanissevich repair is an inguinal approach with an attempt, though sometimes unsuccessful, to preserve the artery, while in the Palomo repair, the internal spermatic cord is tied off 'en masse' (i.e., inclusive of artery, lymphatics, and veins at a point proximal to the joining of the vas deferens to the cord). Because failure rates in adolescents with the customarily employed Ivanissevich repair approached $14-16 \%$, the Palomo repair became popular, especially after Kass and Marco reported no failures in 62 Palomo varicocelectomies $[24,25]$. However, in a more recent study by the same group, the incidence of recurrence rose to $3.9 \%$ along with a $29 \%$ incidence of hydrocele formation when the number of patients increased to 233 [26]. Because of the high incidence of postoperative hydroceles (though with a considerably smaller percentage requiring actual hydrocelectomy), alternative repairs have been sought.

The laparoscopic 'en masse' ligation essentially is a Palomo repair, but because dissection ends up skeletonizing the cord more than in the Palomo repair, some lymphatics are likely left behind, and thus there is a lower incidence of post-varicocelectomy hydroceles [27].

In a recent publication by Poon et al. [28], the role of lymphatic-sparing (LS) effect on catch-up growth was examined. In this study of 136 boys (mean age 15.1 years) with greater than $10 \%$ asymmetry, 107 were treated with laparoscopic LS and 29 underwent lymphatic non-sparing (LNS) varicocelectomy between 1997 and 2006. Catch-up growth was achieved in $62.8 \%$ of patients, but there was no significant difference between the two approaches with regard to catch-up growth $(51.7 \%$ versus $66.3 \%$, $P=0.193$ ) [28]. Alternately, in a recent meeting of the
European Society for Paediatric Urology, Kocvara et al. [29] presented their 10-year experience with LNS $(n=37)$ and LS ( $\mathrm{n}=137)$ varicocelectomies. After a follow-up of 3.7 years, the authors noted a significantly higher increase in testicular size across all pubertal stages in the LNS group compared with the LS group. Although they did not report catch-up growth rates, the authors attributed the difference in testicular volume measurements to intratesticular edema from vascular congestion in the LNS group, suggesting that catch-up growth can be accurately assessed only in microsurgical LS repair [29].

Some have suggested laparoscopic and subinguinal microscopic LS varicocelectomies as an alternative to reduce the incidence of hydroceles, and one group has suggested using the microscope during the Palomo repair to identify the lymphatics, but not necessarily the artery [30]. Another group has advocated the use of isosulfan blue to aid in lymphatic identification [31]. We started to isolate the lymphatics laparoscopically, where magnification is often similar to that in microscopic repair, and we noted a reduction in the incidence of hydroceles from $11.4 \%$ to $3.4 \%$, with less than $1 \%$ of patients requiring hydrocelectomy [32]. Others have sought to save the artery, and unfortunately in some reports of subinguinal varicocelectomy, there has been a higher recurrence rate and an occasional episode of testicular atrophy. Such a risk of testicular atrophy is potentially more likely when a patient has undergone previous inguinal surgery in which vasculature that supports the testicle may already be compromised. A recent analysis by Woldu et al. [33] addressed this concern by examining 22 patients who had a prior history of ipsilateral inguinal surgery and who underwent unilateral or bilateral varicocele repair. After a median follow-up of 24.2 months, there was no incidence of postoperative testicular atrophy. Testicular asymmetry decreased from $27.6 \%$ to $10.5 \%$ and the incidence of catch-up growth was $43 \%$, with no difference between the artery-sparing and non-arterysparing techniques [33].

\section{Implications for clinical practice}

Adolescents with varicoceles represent a large and heterogeneous group. This patient population has rapidly changing hormonal levels and may present at different stages of physical and pubertal development. A standard approach to these patients may not be possible. We recommend instead an individualized approach in which all parameters, including physical findings, percentage asymmetry, and abnormal DDUS parameters, are considered and are used as part of an overall clinical decision. Currently, there are no parameters that can predict impairment of fertility in 
adulthood for these patients. The ideal clinical follow-up protocol as well as the indications for surgical intervention and the optimal choice for the operative approach continue to be debated.

\section{Abbreviations}

DDUS, duplex Doppler ultrasound; LNS, lymphatic nonsparing; LS, lymphatic-sparing; PRF, peak retrograde flow.

\section{Competing interests}

The authors declare that they have no competing interests.

\section{References}

I. Steeno O, Knops J, Declerck L, Adimoelja A, van de Voorde H: Prevention of fertility disorders by detection and treatment of varicocele at school and college age. Andrologia 1976, 8:47-53.

2. Oster J: Varicocele in children and adolescents. An investigation of the incidence among Danish school children. Scand J Urol Nephrol 1971, 5:27-32.

3. Risser WL, Lipshultz LI: Frequency of varicocele in black adolescents. J Adolesc Health Care 1984, 5:28-9.

4. Greenberg SH, Lipshultz LI, Wein AJ: Experience with $\mathbf{4 2 5}$ subfertile male patients. J Urol 1978, I I9:507-I0.

5. $\quad$ Pryor JL, Howards SS: Varicocele. Urol Clin North Am 1987, I4:499513.

6. Mori M, Bertolla R, Fraietta R, Ortiz V, Cedenho A: Does varicocele grade determine extent of alteration to spermatogenesis in adolescents? Fertil Steril 2008, 90:1769-73.

FI000 Factor 6.0 Must Read

Evaluated by Jay Sandlow 31 Jan 2008

7. Cayan S, Acar D, Ulger S, Akbay E: Adolescent varicocele repair: long-term results and comparison of surgical techniques according to optical magnification use in 100 cases at a single university hospital. J Urol 2005, I74:2003-6; discussion 2006-7.

8. Kass EJ, Belman $A B$ : Reversal of testicular growth failure by varicocele ligation. J Urol 1987, I37:475-6.

9. Sigman M, Jarow JP: Ipsilateral testicular hypotrophy is associated with decreased sperm counts in infertile men with varicoceles. J Urol I997, I 58:605-7.

10. Lipshultz LI, Corriere JN Jr: Progressive testicular atrophy in the varicocele patient. J Urol 1977, I I7:175-6.

II. Chehval MJ, Purcell MH: Deterioration of semen parameters over time in men with untreated varicocele: evidence of progressive testicular damage. Fertil Steril 1992, 57:174-7.

12. Haans LC, Laven JS, Mali WP, te Velde ER, Wensing CJ: Testis volumes, semen quality, and hormonal patterns in adolescents with and without a varicocele. Fertil Steril 1991, 56:73 I-6.

13. Okuyama A, Nakamura M, Namiki M, Takeyama M, Utsunomiya M, Fujioka H, Itatani H, Matsuda M, Matsumoto K, Sonoda T: Surgical repair of varicocele at puberty: preventive treatment for fertility improvement. J Urol 1988, I39:562-4.

14. Alukal JP, Zurakowski D, Atala A, Bauer SB, Borer JG, Cilento BG Jr, Mandell J, Peters CA, Paltiel HJ, Retik AB, Diamond DA: Testicular hypotrophy does not correlate with grade of adolescent varicocele. J Urol 2005, I74:2367-70; discussion 2370.

I5. Thomas JC, Elder JS: Testicular growth arrest and adolescent varicocele: does varicocele size make a difference? J Urol 2002, 168:|689-9|.

16. Kass EJ, Freitas JE, Bour JB: Adolescent varicocele: objective indications for treatment. J Urol 1989, I 42:579-82; discussion 603-5.
17. Diamond DA, Zurakowski D, Bauer SB, Borer JG, Peters CA, Cilento BG Jr, Paltiel HJ, Rosoklija I, Retik AB: Relationship of varicocele grade and testicular hypotrophy to semen parameters in adolescents. J Urol 2007, I78: I584-8.

18. Kolon TF, Clement MR, Cartwright L, Bellah R, Carr MC, Canning DA, Snyder HM 3rd: Transient asynchronous testicular growth in adolescent males with a varicocele. J Urol 2008, I80: I | | |-4; discussion I | |4-5.

19. Poon SA, Gjertson CK, Mercado MA, Raimondi PM, Kozakowski KA, Glassberg KI: Testicular asymmetry and adolescent varicoceles managed expectantly. J Urol 2010, 183:731-4.

FI000 Factor 3.0 Recommended

Evaluated by Emilio Merlini 25 Feb 2010

20. Salzhauer EW, Sokol A, Glassberg KI: Paternity after adolescent varicocele repair. Pediatrics 2004, I | 4: I63 I-3.

21. Cayan S, Akbay E, Bozlu M, Doruk E, Yildiz A, Acar D, Kanik EA, Ulusoy E: Diagnosis of pediatric varicoceles by physical examination and ultrasonography and measurement of the testicular volume: using the prader orchidometer versus ultrasonography. Urol Int 2002, 69:293-6.

22. Diamond DA, Paltiel HJ, DiCanzio J, Zurakowski D, Bauer SB, Atala A, Ephraim PL, Grant R, Retik AB: Comparative assessment of pediatric testicular volume: orchidometer versus ultrasound. J Urol 2000, 164: I I II-4.

23. Kozakowski KA, Gjertson CK, Decastro GJ, Poon S, Gasalberti A, Glassberg KI: Peak retrograde flow: a novel predictor of persistent, progressive and new onset asymmetry in adolescent varicocele. J Urol 2009, I81:2717-22; discussion 2723.

24. Kass EJ, Marcol B: Results of varicocele surgery in adolescents: a comparison of techniques. J Urol 1992, I 48:694-6.

25. Misseri R, Gershbein AB, Horowitz M, Glassberg KI: The adolescent varicocele. II: the incidence of hydrocele and delayed recurrent varicocele after varicocelectomy in a long-term follow-up. BJU Int 200I, 87:494-8.

26. Feber KM, Kass EJ: Varicocelectomy in adolescent boys: longterm experience with the Palomo procedure. J Urol 2008, 180: 1657-9; discussion 1659-60.

27. McManus MC, Barqawi A, Meacham RB, Furness PD 3rd, Koyle MA: Laparoscopic varicocele ligation: are there advantages compared with the microscopic subinguinal approach? Urology 2004, 64:357-60; discussion 360-I.

28. Poon SA, Kozakowski KA, Decastro GJ, Gjertson CK, Glassberg KI: Adolescent varicocelectomy: postoperative catch-up growth is not secondary to lymphatic ligation. J Pediatr Urol 2009, 5:37-4I.

29. Kocvara R, Sedlacek J, Dite Z, Molcan J, Dvoracek J: Testicular size and catch-up growth after lymphatic-sparing and lymphatic non-sparing varicocele repair in children and adolescents. J Pediatr Urol 2009, 5(Suppl I):S8I.

30. Watanabe M, Nagai A, Kusumi N, Tsuboi H, Nasu Y, Kumon H: Minimal invasiveness and effectivity of subinguinal microscopic varicocelectomy: a comparative study with retroperitoneal high and laparoscopic approaches. Int J Urol 2005, 1 2:892-8.

Changes Clinical Practice

FI000 Factor 3.0 Recommended

Evaluated by Evan Kass 20 Feb 2006

31. Schwentner C, Oswald J, Lunacek A, Deibl M, Bartsch G, Radmayr C: Optimizing the outcome of microsurgical subinguinal varicocelectomy using isosulfan blue: a prospective randomized trial. J Urol 2006, I 75:1049-52.

32. Glassberg KI, Poon SA, Gjertson CK, DeCastro GJ, Misseri R: Laparoscopic lymphatic sparing varicocelectomy in adolescents. J Urol 2008, I80:326-30; discussion 330-I.

33. Woldu S, Poon S, Raimondi P, Glassberg K: Is adolescent varicocelectomy safe after previous inguinal surgery? J Urol 2010 , in press. 